Originalartikkel

\title{
Kirurgisk behandling av benigne gynekologiske lidelser
}

\begin{abstract}
Sammendrag
Bakgrunn. I Norge skal alle ha tilgang på gode og likeverdige helsetjenester. Formålet med denne undersøkelsen var å kartlegge om behandlingen av kvinner med godartede gynekologiske lidelser er i overensstemmelse med dette. Ved kirurgisk behandling av kvinner med ektopisk graviditet og ovariecyster anbefales laparoskopi. Hysterektomi bør gjøres med vaginal eller laparoskopisk teknikk.
\end{abstract}

Materiale og metode. Vi har registrert operasjonsmetode ved kirurgisk behandling av ektopisk graviditet, ovariecyster og ved hysterektomi på indikasjon blødningsforstyrrelse og/eller muskelknute ved de gynekologiske avdelingene i Norge. Tallmaterialet er hentet fra Nasjonalt pasientregister for perioden 2003-06.

Resultater. Andelen operasjoner utført med laparotomi reduseres gradvis for de aktuelle tilstandene i løpet av registreringsperioden. I 2003 ble $24 \%$ av kvinnene med ektopisk graviditet og $50 \%$ av kvinnene med ovariecyster behandlet med laparotomi. De tilsvarende tallene for 2006 var henholdsvis $14 \%$ og $41 \%$. Ved hysterektomi på grunn av blødningsforstyrrelser og/eller muskelknuter falt andelen laparotomi fra $75 \%$ i 2003 til $62 \%$ i 2006. Store avdelinger behandler oftere i overensstemmelse med gjeldende retningslinjer.

Fortolkning. Kvinner i Norge tilbys ulik behandling for samme gynekologiske lidelse. Vi har ikke evaluert årsakene til variasjonen i behandlingstilbudet, men mulige forklaringer kan være ulik behandlingstradisjon, manglende kompetanse og utilstrekkelig opplæring av gynekologer.

\author{
Jeanne Mette Goderstad \\ jeannemette.goderstad@ulleval.no \\ Marit Lieng \\ Bjørn Busund \\ Kvinnesenteret \\ Oslo universitetssykehus, Ullevål \\ 0403 Oslo
}

Det er et grunnleggende prinsipp i Norge at alle skal ha tilgang til gode og likeverdige helsetjenester (1). Laparoskopisk kirurgi og vaginal hysterektomi gir mindre postoperative smerter, lavere risiko for sårinfeksjoner, kortere sykehusinnleggelse, raskere rekonvalesens og redusert sykmeldingslengde sammenliknet med laparotomi (2).

Den nasjonale veilederen for generell gynekologi anbefaler laparoskopi ved kirurgisk behandling av kvinner med ektopisk graviditet (3). Det foreligger også internasjonale studier som konkluderer med dette (4). Veilederen har derimot ingen klar anbefaling av kirurgisk teknikk for behandling av benigne ovariecyster. The Royal College of Obstetricians and Gynaecologists (RCOG) anbefaler laparoskopi ved kirurgisk behandling av benigne ovariecyster (5). I 2005 ble konklusjonen av en gjennomgang av eksisterende dokumentasjon at laparoskopi bør benyttes ved kirurgisk behandling av godartede cyster på eggstokkene (6).

Hysterektomi kan utføres vaginalt, åpent eller med laparoskopisk teknikk. Vi har ingen nasjonale retningslinjer for hvilken operasjonsmetode som bør benyttes. I enkelte internasjonale studier konkluderer man med at vaginal hysterektomi bør foretrekkes. Laparoskopisk hysterektomi bør velges om kvinnen ikke egner seg for vaginal hysterektomi $(2,7)$. Tidligere studier har vist at valg av metode for hysterektomi varierer ved gynekologiske avdelinger i Norge $(8,9)$. Vi ønsker med denne undersøkelsen å kartlegge om kvinner i Norge får et godt og likeverdig tilbud ved operativ behandling av benigne gynekologiske lidelser.

\section{Materiale og metode}

Tallmaterialet er hentet fra Norsk pasientregister (NPR) for perioden 1.1. 2003-31.12. 2006. Det ble søkt på ICD-10-diagnosekoder og prosedyrekoder. For tilstandene ektopisk graviditet og ovariecyster registrerte vi antall kvinner behandlet med laparoskopisk prosedyre og antall behandlet med laparotomi. For hysterektomi på indikasjon blødningsforstyrrelse og/eller muskelknute registrerte vi antall kvinner som fikk utført vaginal hysterektomi, laparoskopisk hysterektomi og hysterektomi utført med laparotomi. Alle operasjonsmetoder som beskriver kirurgisk behandling av ektopisk graviditet, benigne ovariecyster og hysterektomi på grunn av blødningsforstyrrelser og/eller muskelknuter ble inkludert (tab 1). Alle sykehus som hadde utført disse inngrepene i løpet av registreringsperioden ble inkludert i studien.

De private sykehusene skiller seg fra offentlige sykehus ved at de ikke har leger i spesialistutdanning. Videre er det tenkelig at leger som arbeider ved private sykehus har spesialisert seg på en type inngrep og at pasientene derfor selekteres. Ved Radiumhospitalet behandles bare kvinner med ondartet eller mistanke om ondartet lidelse. De private sykehusene (Volvat medisinske senter, Axess sykehus og spesialistklinikk og Omnia Røde Kors Klinikk (Aleris)) og Det Norske Radiumhospital ble derfor utelatt fra analysene. De gynekologiske avdelingene ble inndelt i mindre og større avdelinger basert på antall prosedyrer per år. Inndelingen er skjønnsbasert, da det ikke finnes noen etablert definisjon på hva som er en stor og hva som er en liten gynekologisk avdeling. Det finnes definisjoner på store og små fødeavdelinger, men denne inndelingen reflekterer ikke alltid den operative gynekologiske aktiviteten ved avdelingene. Grensen mellom små og store avdelinger valgte vi å sette på 20 inngrep per år for ektopisk graviditet, 50 inngrep per år for ovariecyster og 100 hysterektomier årlig på indikasjonen blødningsforstyrrelser og/eller muskelknuter. Ved denne inndelingen karakteriseres $10-30 \%$ av landets avdelinger som store og resten som små. Analysene ble også utført ved andre inndelinger for å sikre at de valgte grensene mellom små og store avdelinger

\section{Hovedbudskap}

- Kvinner i Norge tilbys ulik kirurgisk behandling for samme gynekologiske lidelse

- De operative ferdighetskravene i spesialistutdanningen bør endres slik at anbefalte teknikker læres

- Gynekologiske avdelingers prosedyrevalg bør registreres og brukes som et kvalitetsmål 
ikke var avgjørende for resultatet av undersøkelsen.

\section{Statistiske analyser}

SPSS for Windows versjon 14.0 ble benyttet under de statistiske analysene. Binomiske variabler i to grupper ble sammenliknet med khikvadrattest. Alle statistiske tester ble gjort tosidig og med signifikansnivå på $5 \%$. Regional forskningsetisk komité ble kontaktet, og de hadde ingen innvendinger til prosjektet.

\section{Resultater}

Totalt 51 avdelinger rapporterte kirurgisk behandling av ektopisk graviditet, ovariecyster og hysterektomi utført på indikasjonene blødningsforstyrrelse og/eller muskelknuter. For alle prosedyrer ble antallet avdelinger redusert i løpet av registreringsperioden $(\operatorname{tab} 2)$.

\section{Ektopisk graviditet}

Det var stor variasjon i antall behandlinger per avdeling per år (fig 1). Et stort antall avdelinger (85\%) utførte under 20 kirurgiske behandlinger årlig, og $61 \%$ av avdelingene utførte færre enn ti slike prosedyrer per år. Den totale andelen laparotomi falt fra $24 \%$ i 2003 til $14 \%$ i 2006 ( $<<0,001)$. Andelen laparotomi ved behandling av ektopisk graviditet falt ved både små og store avdelinger $\mathrm{i}$ registreringsperioden ( $\operatorname{tab} 2$ ). Om grensen mellom store og små avdelinger settes ved ti prosedyrer per år, viser analysene fortsatt en signifikant lavere andel laparotomi ved de store avdelingene $(12 \%)$ sammenliknet med ved de små $(27 \%)$, $\mathrm{p}<0,001$, RR 2,25 (95\% KI 1,50-3,37).

\section{Ovariecyste}

Det var stor variasjon i antall behandlinger per avdeling per år. Vi så også tendens til forskjell mellom de ulike helseregionene i valg av operasjonsteknikk (fig 2). I 2006 utførte 33 avdelinger $(75 \%)$ under 50 kirurgiske behandlinger av godartede ovarialcyster, mens 23 avdelinger (52\%) utførte under 20 cysteoperasjoner.

Den totale andelen laparotomiinngrep falt fra 50\% i 2003 til $41 \%$ i 2006 (p <0,001). Ved behandling av ovariecyster falt den ved både små og store avdelinger i registreringsperioden ( $\operatorname{tab} 2$ ). Om grensen mellom store og små avdelinger settes ved 20 cysteoperasjoner per år, viser analysene fortsatt en signifikant lavere andel laparotomibehandlinger ved de store avdelingene (37\%) sammenliknet med de små (66\%), p < 0,001, RR $1,76(95 \%$ KI 1,56-1,98).

\section{Hysterektomi}

Det var stor variasjon i antall behandlinger per avdeling per år. Det var også tendens til forskjeller mellom helseregionene i valg av operasjonsmetode (fig 3). Laparotomi var den dominerende operasjonsmetoden ved hysterektomi. Den totale andelen åpen hys-
Tabell 1 Diagnosekoder og prosedyrekoder benyttet under søk i Norsk pasientregister i perioden 2003-06

\begin{tabular}{|c|c|c|c|}
\hline & & $\begin{array}{l}\text { Diagnosekode } \\
\text { (ICD-10) }\end{array}$ & Prosedyrekode \\
\hline Ektopisk graviditet & & $0-001$ & $\begin{array}{l}\text { LBC11, LBC21, LBC97, LBD01, LBE01, } \\
\text { LBC10, LBC20, LBC96, LBD00, LBE00 }\end{array}$ \\
\hline Ovariecyste & & D-27, N-83.2 & $\begin{array}{l}\text { LAC01, LAC11, LAC21, LAC 31, LAC97, } \\
\text { LAD01, LAE11, LAF11, LAE21, LAF01, } \\
\text { LAF11, LAC00, LAC10, LAC20, LAC30, } \\
\text { LAC96, LAD00, LAE20, LAF00, LAF10 }\end{array}$ \\
\hline \multirow[t]{2}{*}{ Hysterektomi } & $\begin{array}{l}\text { Blødnings- } \\
\text { forstyrrelser }\end{array}$ & $N-92.1$ & $\begin{array}{l}\text { LCC11, LCD01, LCD04, LCD10, LCD11, } \\
\text { LCC10, LCD00 }\end{array}$ \\
\hline & Myoma uteri & D-25.0, D-25.9 & \\
\hline
\end{tabular}

terektomi falt fra $75 \%$ i 2003 til $62 \%$ i 2006 $(\mathrm{p}<0,001)$. I 2006 var andelen vaginale hysterektomier i de forskjellige avdelingene $0-69 \%$, og andelen laparoskopiske hysterektomier $0-70 \%$.

Andelen laparotomiinngrep falt ved både små og store avdelinger i løpet av registreringsperioden (tab 2). Om grensen mellom store og små avdelinger settes ved 50 hysterektomier per år, viser analysene fortsatt en signifikant lavere andel laparotomier ved de store avdelingene (62\%) sammenliknet med

ved de små (85 \%), p < 0,001, RR 1,36 (95\% KI 1,29-1,42).

Antallet vaginale hysterektomier utført på indikasjonene blødningsforstyrrelser og/ eller muskelknuter holdt seg relativt konstant, mens antallet laparoskopiske hysterektomier viste en stigende tendens i registreringsperioden (fig 4).

\section{Diskusjon}

Våre funn viser at kvinner i Norge tilbys ulik operativ behandling for benigne gynekolo-

Tabell 2 Laparotomi ved kirurgisk behandling av ektopisk graviditet, ovariecyste og hysterektomi på indikasjonen blødningsforstyrrelse og/eller myoma uteri ved mindre og større gynekologiske avdelinger

\begin{tabular}{|c|c|c|c|c|c|c|c|}
\hline \multirow[t]{9}{*}{$\begin{array}{l}\text { Ekstra- } \\
\text { uterin } \\
\text { graviditet }\end{array}$} & $\AA ̊ r$ & $\begin{array}{c}\text { Antall } \\
\text { operasjo- } \\
\text { ner per år }\end{array}$ & $\begin{array}{c}\text { Antall } \\
\text { avdelinger }\end{array}$ & $\begin{array}{l}\text { Antall } \\
\text { kvinner }\end{array}$ & $\begin{array}{c}\text { Antall laparo- } \\
\text { tomier (\%) }\end{array}$ & P-verdi ${ }^{1}$ & $\begin{array}{l}\text { Relativ risiko } \\
\text { (95\% KI) }\end{array}$ \\
\hline & \multirow[t]{2}{*}{2003} & $<20$ & 37 & 261 & $83(31,8)$ & \multirow[b]{2}{*}{$<0,001$} & \multirow{2}{*}{$\begin{array}{c}1,85 \\
(1,36-2,52)\end{array}$} \\
\hline & & $\geq 20$ & 7 & 285 & $49(17,2)$ & & \\
\hline & \multirow[t]{2}{*}{2004} & $<20$ & 35 & 235 & $76(32,3)$ & \multirow[b]{2}{*}{$<0,001$} & \multirow{2}{*}{$\begin{array}{c}3,13 \\
(2,15-4,54)\end{array}$} \\
\hline & & $\geq 20$ & 8 & 319 & $33(10,3)$ & & \\
\hline & \multirow[t]{2}{*}{2005} & $<20$ & 37 & 258 & $68(26,3)$ & \multirow[b]{2}{*}{$<0,001$} & \multirow{2}{*}{$\begin{array}{c}3,14 \\
(2,00-4,92)\end{array}$} \\
\hline & & $\geq 20$ & 7 & 262 & $22(8,4)$ & & \\
\hline & \multirow[t]{2}{*}{2006} & $<20$ & 32 & 245 & $55(22,4)$ & \multirow[b]{2}{*}{$<0,001$} & \multirow{2}{*}{$\begin{array}{c}2,72 \\
(1,76-4,20)\end{array}$} \\
\hline & & $\geq 20$ & 7 & 315 & $26(8,3)$ & & \\
\hline \multirow{8}{*}{$\begin{array}{l}\text { Ovarie- } \\
\text { cyste }\end{array}$} & \multirow[t]{2}{*}{2003} & $<50$ & 34 & 593 & $346(58,3)$ & \multirow[b]{2}{*}{$<0,001$} & \multirow{2}{*}{$\begin{array}{c}1,29 \\
(1,17-1,42)\end{array}$} \\
\hline & & $\geq 50$ & 12 & 989 & $448(45,3)$ & & \\
\hline & \multirow[t]{2}{*}{2004} & $<50$ & 34 & 565 & $320(56,6)$ & \multirow[b]{2}{*}{$<0,001$} & \multirow{2}{*}{$\begin{array}{c}1,55 \\
(1,39-1,72)\end{array}$} \\
\hline & & $\geq 50$ & 12 & 1022 & $374(36,6)$ & & \\
\hline & \multirow[t]{2}{*}{2005} & $<50$ & 36 & 741 & $390(52,6)$ & \multirow[b]{2}{*}{$<0,001$} & \multirow{2}{*}{$\begin{array}{c}1,72 \\
(1,53-1,94)\end{array}$} \\
\hline & & $\geq 50$ & 9 & 874 & $267(30,5)$ & & \\
\hline & \multirow[t]{2}{*}{2006} & $<50$ & 33 & 658 & $356(54,1)$ & \multirow[b]{2}{*}{$<0,001$} & \multirow{2}{*}{$\begin{array}{c}1,66 \\
(1,48-1,87)\end{array}$} \\
\hline & & $\geq 50$ & 11 & 981 & $319(32,5)$ & & \\
\hline \multirow{8}{*}{$\begin{array}{l}\text { Hyster- } \\
\text { ektomi }\end{array}$} & \multirow[t]{2}{*}{2003} & $<100$ & 32 & 1323 & $1106(83,6)$ & \multirow[b]{2}{*}{$<0,001$} & \multirow{2}{*}{$\begin{array}{c}1,21 \\
(1,17-1,25)\end{array}$} \\
\hline & & $\geq 100$ & 15 & 2198 & $1519(69,1)$ & & \\
\hline & \multirow[t]{2}{*}{2004} & $<100$ & 34 & 1528 & $1195(78,2)$ & \multirow[b]{2}{*}{$<0,001$} & \multirow{2}{*}{$\begin{array}{c}1,25 \\
(1,20-1,31)\end{array}$} \\
\hline & & $\geq 100$ & 13 & 2024 & $1263(62,4)$ & & \\
\hline & 2005 & $<100$ & 34 & 1595 & $1182(74,1)$ & & 1,29 \\
\hline & & $\geq 100$ & 11 & 1727 & $995(57,6)$ & $<0,001$ & $(1,22-1,35)$ \\
\hline & 2006 & $<100$ & 33 & 1501 & $1062(70,8)$ & & \\
\hline & & $\geq 100$ & 11 & 1614 & $897(55,6)$ & $<0,001$ & $(1,21-1,34)$ \\
\hline
\end{tabular}

1 Khikvadrattest 


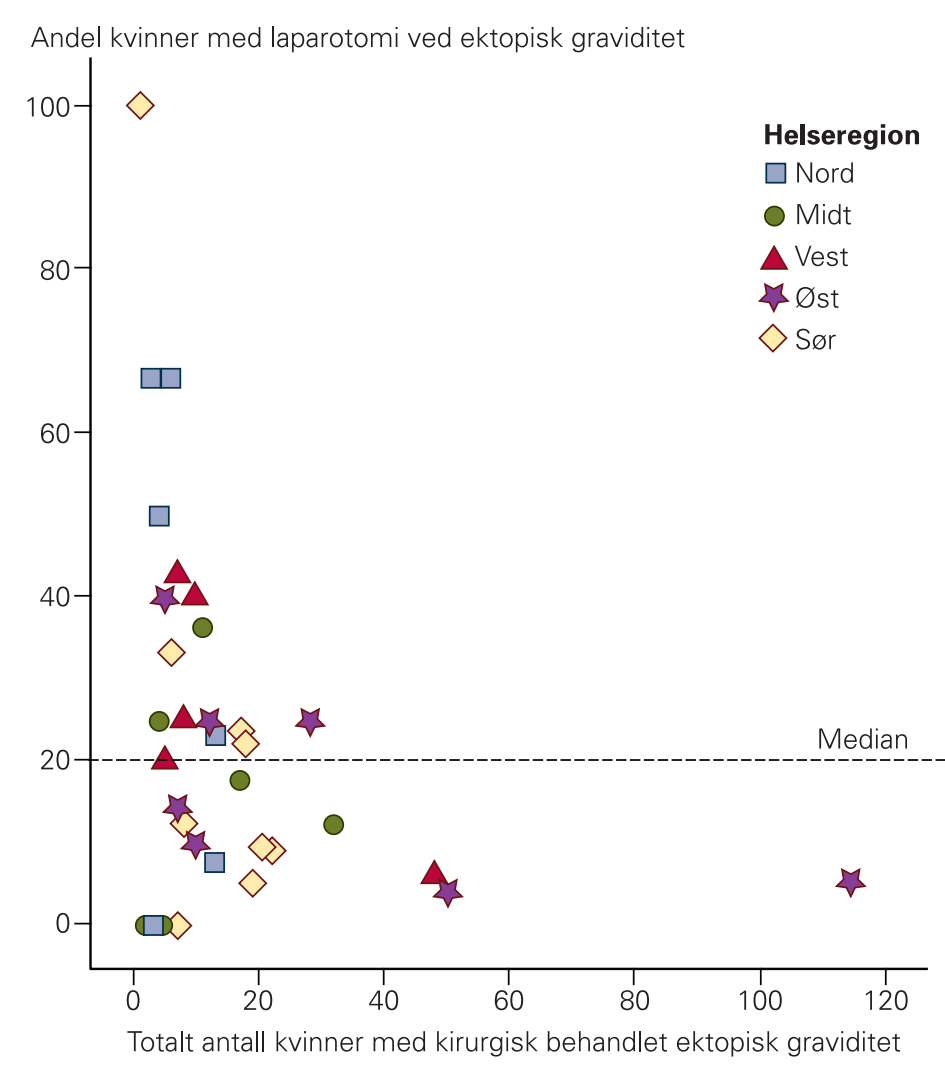

Figur 1 Fordeling av gynekologiske avdelinger ut fra antall kvinner med ektopisk graviditet behandlet med laparotomi i 2006 . Hver prikk representerer et sykehus

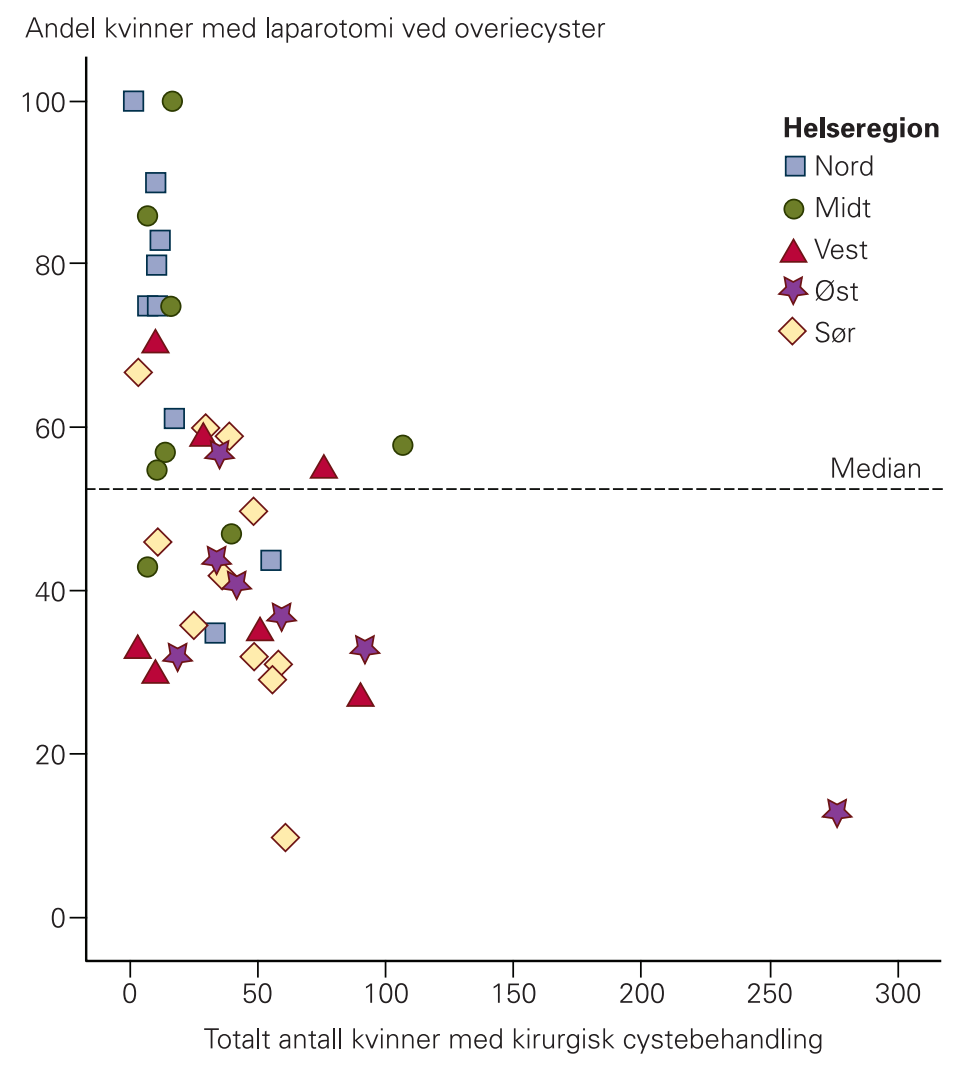

Figur 2 Fordeling av gynekologiske avdelinger ut fra antall kvinner med ovariecyster behandlet med laparotomi i 2006. Hver prikk representerer et sykehus giske tilstander. Det er forskjeller mellom små og store avdelinger og også tendens til regionsforskjeller. Utvikling $\mathrm{i}$ retning av færre åpne inngrep skjer i større grad ved de store avdelingene enn ved de små.

Våre data er hentet fra Norsk pasientregister (NPR). Kvaliteten på dataene påvirkes av avdelingenes rutiner for innrapportering til dette registeret. Det er tallene i registeret som danner grunnlaget for finansieringen av sykehusdriften. Inngrepene gir samme kronebeløp uavhengig av operasjonsmetode. Det er derfor lite sannsynlig at det foreligger systematiske feilrapporteringer.

Inndelingen i små og store avdelinger er relativt vilkårlig og kan diskuteres. Insidensen av hysterektomi varierer i ulike deler av Norge (8). Dette kan blant annet skyldes ulik aldersfordeling i befolkningen og ulik toleranse for underlivsplager. Varierende tilgang på transcervikale operasjonsmetoder for behandling av blødningsforstyrrelser, ulik tradisjon og ulik tilgang på gynekologisk spesialisthelsetjeneste kan tenkes å spille en rolle.

\section{Hva kan gjøres?}

En nasjonal strategi for å redusere bruken av åpen kirurg ved behandling av benigne gynekologiske tilstander er etter vår mening nødvendig. Innføring av avdelingers prosedyrevalg som et kvalitetsmål på linje med epikrisetid, antall korridorpasienter og keisersnittsfrekvens, kan tenkes å bidra til en positiv utvikling.

I Norge har alle avdelinger tilbud om å være med i et nasjonalt laparoskopiregister. Et nasjonalt register for all gynekologisk kirurgi vil kunne bidra til kvalitetssikring og muligens skape en mer bevisst holdning til valg av kirurgiske prosedyrer.

Hvert år utdannes det i overkant av 20 gynekologer i Norge. I målbeskrivelsen og gjennomføringsplanen for faget fødselshjelp og kvinnesykdommer er det ingen krav til at utdanningskandidaten skal kunne utføre vaginal eller laparoskopisk hysterektomi (10). Endring av ferdighetskravene slik at nyutdannede spesialister kjenner til og kan utføre de anbefalte operasjonsteknikkene er en forutsetning for å få ned laparotomifrekvensen. I spesialistutdanningen inngår ingen obligatoriske kurs i vaginale eller laparoskopiske operasjonsteknikker. Etter vår mening bør dette innføres. Ferdighetstrening i laparoskopisk teknikk kan foregå med simulator eller treningsboks. Norsk gynekologisk forening og spesialitetskomiteen bør fokusere på hvordan den kirurgiske utdanningen av leger i spesialisering i fødselshjelp og kvinnesykdommer kan bedres. Den nasjonale veilederen i generell gynekologi bør revideres, slik at den gir klare anbefalinger om foretrukket operasjonsmetode ved forskjellige tilstander. Etablering av et nasjonalt kompetansesenter for minimal invasiv gynekologisk kirurgi og et i vaginal kirurgi med fokus på kompetanseutvikling for landets gynekologer vil kunne bidra positivt. 


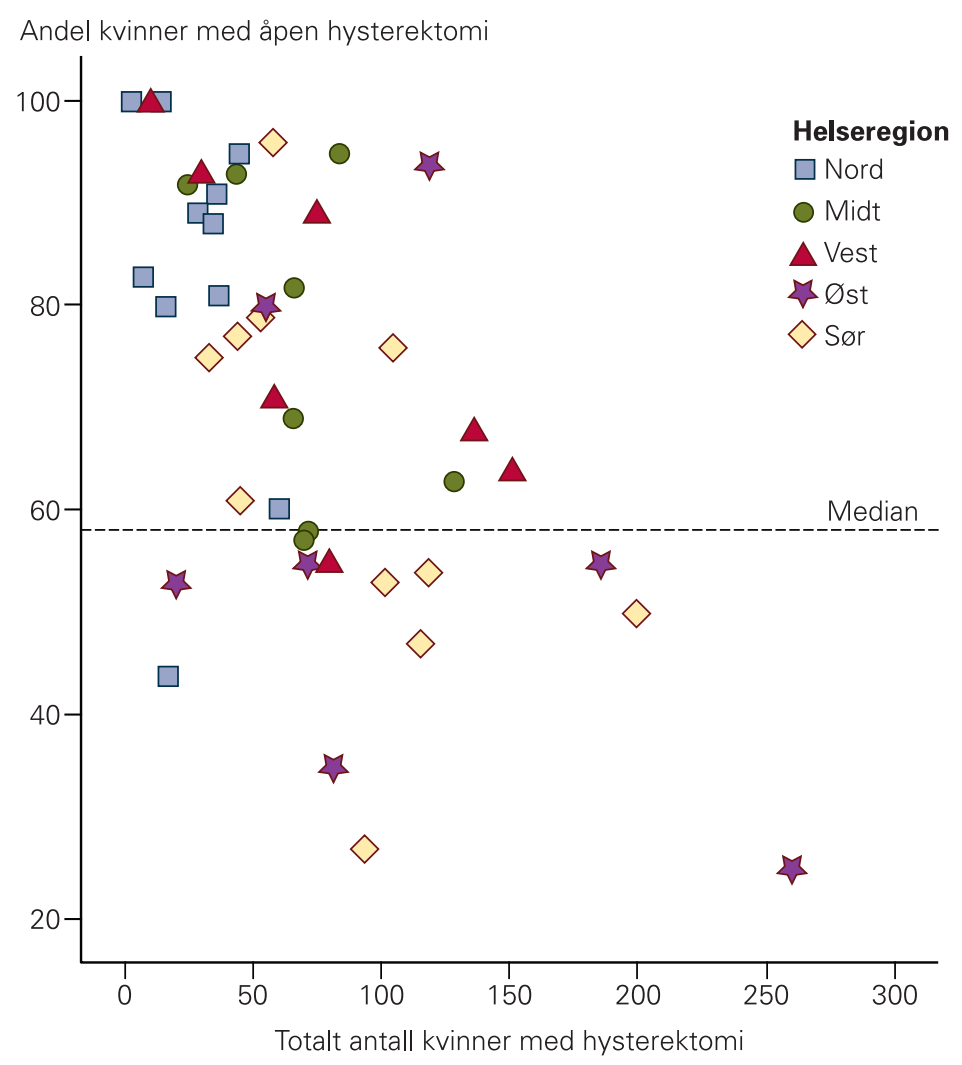

Figur 3 Fordeling av gynekologiske avdelinger ut fra antall åpne hysterektomier i 2006. Hver prikk representerer et sykehus

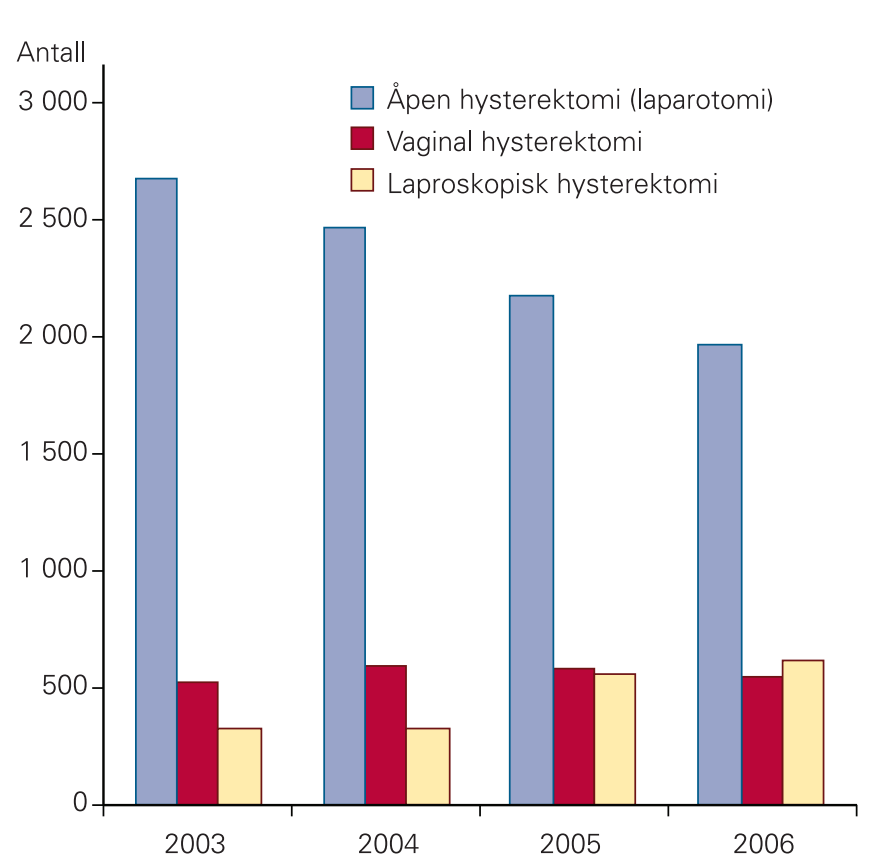

Figur 4 Hysterektomier i Norge på grunn av blødningsforstyrrelser og/eller myoma uteri i perioden 2003-06

\section{Konklusjon}

Denne undersøkelsen viser at kvinner i Norge ikke får et likeverdig tilbud ved kirurgisk behandling av benigne gynekologiske tilstander. Årsakene til variasjonen i behandlingstilbudet er ikke evaluert, men kan skyldes ulik behandlingstradisjon, manglende kompetanse og utilstrekkelig opplæring i alternative teknikker til laparotomi.

Takk til Therese Opsahl Holte og Inger Natvig Norderhaug ved Nasjonalt kunnskapssenter for helsetjenesten for bidrag under datainnsamlingen og nyttige innspill under bearbeidingen av data og utarbeidingen av manuskriptet. Vi ønsker også å takke May-Britt Aronsen ved Norsk pasientregister for samarbeidet.

Oppgitte interessekonflikter: Ingen

\section{Litteratur}

1. Norges offentlige utredninger. Fordeling av inntekter mellom regionale helseforetak. NOU 2008. 2.

2. Johnson N, Barlow D, Lethaby A et al. Surgical approach to hysterectomy for benign gyneacological disease. Cochrane Database Syst Rev 2006; nr. 2: CD003677.

3. Langebrekke A, Jerve F. Ekstrauterin graviditet. I: Moen MH, Skjeldestad FE, red. Veileder i generell gynekologi i 2004. Oslo: Den norske lægeforening, 2004: 27-32.

4. Hajenius PJ, Mol F, Mol BWJ et al. Interventions for tubal ectopic pregnancy. Cochrane Database Syst Rev 2000; nr 1: CD000324.

5. Royal College of Obstetricians and Gynaecologists (RCOG). Ovarian cysts in postmenopausal women. Guideline No. 34. London: Royal College of Obstetricians and Gynaecologists (RCOG), 2003.

6. Medeiros LR, Fachel JMG, Garry R et al. Laparoscopy versus laparotomy for benign ovarian tumors. Cochrane Database Syst Rev 2005; nr. 3 : CD0004751.

7. Garry R. The future of hysterectomy. BJOG 2004; 112: 133-9.

8. Kalseth B, Røttingen JA, red. Praksis og kvalitet ved norske sykehus: pasienterfaringer, personellerfaringer, overlevelsesrater som kvalitetsindikator, praksisvariasjoner. SINTEF-rapport. Oslo: SINTEF, 2002.

9. Oma J. Hvilke faktorer avgjør metodevalget ved hysterektomi på benign indikasjon? Tidsskr Nor Lægeforen 2004; 124: 792-4.

10. Den norske legeforening. Spesialiteter. Fødselshjelp og kvinnesykdommer. Målbeskrivelse og gjennomføringsplan. www.legeforeningen.no/id/ 1297.0 (2.4.2009.)

Manuskriptet ble mottatt 7.7. 2008 og godkjent 2.4. 2009. Medisinsk redaktør Are Brean. 